\title{
Use of Omalizumab to treat a nine-year old, with steroid-dependent, allergic asthma, adrenal insufficiency and vertebral compression fractures due to steroid induced severe osteoporosis
}

Alicia Ring ${ }^{1 *}$, Caroline Rizk², Stephanie Santucci ${ }^{1}$, Joanne Desormeaux ${ }^{1}$, lan MacLuskey ${ }^{2}$, Jacob Karsh ${ }^{2}$, William H Yang ${ }^{1,2}$

From Canadian Society of Allergy and Clinical Immunology Annual Scientific Meeting 2011

Quebec, Canada. 20-23 October 2011

\section{Background}

In Canada, Omalizumab is indicated for adults and adolescents with moderate to severe persistent allergic asthma, but not for pediatric use $(<12$ years of age). A 9 year-old boy with steroid dependent, allergic asthma, multiple ICU admissions and severe back pain from compression fractures was referred to our centre. IgE was $1337 \mathrm{IU} / \mathrm{ml}$. Skin prick testing showed multiple positive reactions. Asthma treatment included inhaled corticosteroids and frequent courses of oral prednisone.

\section{Methods}

After obtaining necessary approvals and informed consents, Omalizumab treatment, $375 \mathrm{mg}$ every 2 weeks, was initiated in September 2010. Serum cortisol levels, bone density, spirometry, and PAQLQ were used to monitor clinical response.

\section{Results}

After 11 months, the changes below were noted.

\section{Conclusions}

The patient improved and was off oral/inhaled corticosteroids with no asthma exacerbations. Spirometry, serum cortisol, PAQLQ and bone density improved. Prednisone treatment in young asthmatic children can be associated with serious side effects. Omalizumab therapy can permit steroid withdrawal and resolution of side effects.

\section{Author details \\ 'Allergy and Asthma Research Centre, Ottawa, Ontario, Canada, K1Y 4G2. ¿University of Ottawa Medical School, Ottawa, Ontario, Canada.}

Published: 14 November 2011

doi:10.1186/1710-1492-7-S2-A38

Cite this article as: Ring et al:: Use of Omalizumab to treat a nine-year old, with steroid-dependent, allergic asthma, adrenal insufficiency and vertebral compression fractures due to steroid induced severe

osteoporosis. Allergy, Asthma \& Clinical Immunology 2011 7(Suppl 2):A38.

Table 1

\begin{tabular}{|c|c|c|c|c|c|c|}
\hline & Daily Prednisone & Daily ICS dose & FEV1 & ${\text { Serum } \text { cortisol }^{\ddagger}}$ & Bone density $^{*}$ & PAQLQ $^{\dagger}$ \\
\hline $2010^{\mathrm{a}}$ & $30 \mathrm{mg}$ & $800 \mathrm{mcg}$ & $1.46 \mathrm{~L}$ & $12 \mathrm{nmol} / \mathrm{L}$ & $0.626 \mathrm{~g} / \mathrm{cm}^{2}$ & 4.7 \\
\hline $2011^{b}$ & $\mathrm{NIL}$ & $200 \mathrm{mcg}$ & $1.98 \mathrm{~L}$ & $215 \mathrm{nmol} / \mathrm{L}$ & $0.686 \mathrm{~g} / \mathrm{cm}^{2}$ & 7 \\
\hline
\end{tabular}

a Pre Omalizumab treatment.

b Post Omalizumab treatment.

${ }^{\ddagger}$ Morning results, range $185-624 \mathrm{nmol} / \mathrm{L}$.

*Total hip.

${ }^{\dagger}$ Pediatric asthma quality of life questionnaire with standardized activities: low 1 - 7 high.

\footnotetext{
${ }^{1}$ Allergy and Asthma Research Centre, Ottawa, Ontario, Canada, K1Y 4G2
}

Full list of author information is available at the end of the article

(c) 2011 Ring et al; licensee BioMed Central Ltd. This is an open access article distributed under the terms of the Creative Commons 